\title{
Expression of p53 and DR5 in normal and malignant tissues of colorectal cancer: Correlation with advanced stages
}

\author{
AURÉLIE PERRAUD ${ }^{1,2,4}$, HUSSEIN AKIL ${ }^{1,2}$, MICHELLE NOUAILLE $^{4}$, DANIEL PETIT $^{3}$, \\ FRANÇOIS LABROUSSE ${ }^{5}$, MARIE-ODILE JAUBERTEAU ${ }^{1,2}$ and MURIEL MATHONNET ${ }^{1,2,4}$
}

${ }^{1}$ Laboratoire EA 3842, Homéostasie Cellulaire et Pathologies, Faculté de Médecine et de Pharmacie, Université de Limoges, 87025 Limoges Cedex; ${ }^{2}$ Institut Fédératif de Recherche 145, Génomique, Environnement, Immunité, Santé et Thérapeutiques (GEIST), Université de Limoges, 87032 Limoges Cedex; ${ }^{3}$ UMR 1061 INRA, Université de Limoges, 87060 Limoges Cedex; ${ }^{4}$ Service de Chirurgie Digestive Générale et Endocrinienne, ${ }^{5}$ Laboratoire d'Anatomopathologie, Centre Hospitalier Universitaire (CHU), 87042 Limoges Cedex, France

Received February 11, 2011; Accepted April 18, 2011

DOI: 10.3892/or.2011.1404

\begin{abstract}
Apoptosis has to be drastically controlled in organs with important cell turnover such as the colon. Deregulation of this process is often present in tumor progression. Tissues of 82 patients treated for colorectal cancer (CRC) were analyzed using antibodies against AIF, p53, DR4, DR5, cleaved caspase-3 and the TUNEL method to detect apoptosis; whereas staining of Ki-67 was used as a proliferation marker. In situ immunohistochemical analyses were compared in non-tumor (NT) cells from normal adjacent mucous membranes with tumor (T) cells from patients with Stage I $(n=6)$, Stage II $(n=35)$, Stage III $(n=27)$ and Stage IV $(n=14)$ CRC. Results were correlated with the tumor stages and the treatment response of patients to improve the understanding of CRC development. p53 and DR5 expression decreased progressively with CRC stage, suggesting that these proteins are important markers of advanced tumor stages. Moreover, p53 appears as a prognostic factor to predict recurrence-free survival. Including the detection of p53 and DR5 for establishing the diagnosis of $\mathrm{CRC}$ and adapting the treatment to each patient is strongly suggested by our work.
\end{abstract}

\section{Introduction}

Colorectal cancer (CRC) is one of the most common forms of cancer. Despite substantial advances in treatment, it remains the second most deadly disease in the Western world: the highest incidence is found in North America, Western Europe,

Correspondence to: Dr Aurélie Perraud, Laboratoire EA 3842, Homéostasie Cellulaire et Pathologies, Faculté de Médecine et de Pharmacie, Université de Limoges, 2 rue du Dr Marcland, 87025 Limoges Cedex, France

E-mail: aurelie.perraud@unilim.fr

Key words: colorectal cancer, apoptosis, patients, markers of advanced stages
Australia/New Zealand and Japan, the lowest in Asia, Africa and an intermediate is found in parts of South America (1). In 2006, more than 200000 cases of the 1.7 million cancer deaths in Europe were due to CRC without gender distinction (2).

The main prognostic indicator for $\mathrm{CRC}$ is the tumor staging based on the invasion of the parts of the colic wall and defined by the international pathology tumor node metastasis (pTNM) classification system (3). Considerable independent variability in clinical outcome is observed, in particular for Stages II and III, which may be a consequence of altered rates of apoptosis and cell proliferation. Tumor growth is favored if the delicate balance between apoptosis at the top of the crypt and proliferation at the base is altered $(2,4)$.

The cytotoxic action of most chemotherapeutic drugs is mediated through the activation of apoptotic pathways $(2,5)$. First described by Kerr and co-workers (6), apoptosis is a programmed cell death characterized by two major pathways: the extrinsic or death receptor pathway and the intrinsic or mitochondrial pathway (7). In addition, communication between pathways can occur at various stages, with the protein Bid for example (8), and other mechanisms independent of the caspase cascade have been described, including in particular the apoptosis inducing factor (AIF) $(9,10)$.

Despite the increasing therapeutic options, drug resistance remains a major problem. The chemoresistance may be inherent (in part due to the tumor heterogeneity) leading to lack of response, or acquired during the course of treatment, leading to disease recurrence. Different mechanisms have been discovered and resistance to apoptosis becomes increasingly apparent $(11,12)$. In particular, the implication of Decoy TRAIL receptors (DcR1 or TRAIL-R3 and DcR2 or TRAIL-R4) (13) and inhibitory of apoptosis proteins (IAP) (14) has been described. Data on the status of apoptotic protein expression in CRC are numerous but not clear, and often controversial (reviewed in ref. 15).

The aim of our study was to compare the expression of proteins implicated in cell proliferation and apoptosis in tumoral (T) and non-tumoral (NT) human colon tissues from different 
CRC stages. Moreover, results were correlated with clinicopathological parameters for giving information on the tumor environment and in predicting tumor behavior. Because the analysis of cells in their native tissue environment provides the most accurate picture of the in vivo disease state, we chose to undertake an immunohistochemical analysis. Moreover, Willie and co-workers have shown that the inter-nucleosomic cleavage of DNA that occurs during apoptosis can be followed by the TUNEL (terminal deoxynucleotide transferase dUTP nick-end labelling) method introduced by Gavrieli and coworkers (16). Thus, thick paraffin sections $(4 \mu \mathrm{m})$ were subjected to immunohistochemistry using anti-Ki-67, p53, AIF, DR4, DR5 and cleaved caspase-3 antibodies and to in situ hybridization by TUNEL analysis. Correlations with the tumor grade, therapeutic response and survival were established.

\section{Materials and methods}

Patient characteristics. Based on a consecutive analysis and a prospective study, 82 informed patients treated for a CRC between January 2006 and February 2007, at the Limoges University Hospital, were examined with a median follow up of 33 months (range 0-45 months). The first follow-up evaluation was made September 1, 2009, with a median of 33 months (range, 19-47 months). The second follow-up evaluation was made December 15, 2010, with a median of 46 months (range, 25-66 months). Characteristics are summarized in Table I. The standard treatment was the recommended FOLFOX4.

In addition, histologically normal colon from 10 patients who had been treated for benign pathologies such as idiopathic chronic constipation $(n=7)$ or diverticulosis $(n=3)$, constituted the 'Control group'.

Patient follow-up and clinicopathological parameters. The clinical, para-clinical (biology and imagery) and histological parameters of patients were collected, and the post-operative recommended follow-up was made. Based on the CRC surveillance (17), patients were seen within one month following resection, then abdominal ultra sonography and thoracic radiograph were obtained every 3-6 months for the first 3 years then every 6 months for 2 years. Computed tomographic scans were performed if abdominal US or thoracic radiographs were doubtful. The first full colonoscopy was performed 3 years after initial surgery, then once every 5 years. Positron emission tomographic (PET) scans were selectively performed when abnormalities or axial imaging raised the question of recurrence.

The primary end-points were disease-free survival (DFS) defined at the time from inclusion to the first of either confirmed recurrence or death and overall survival (OS) defined at the time from inclusion to death. Local recurrence was defined as the first clinical, radiologic and/or pathologic evidence of tumor of the same histological type within the colon. Distant recurrence was defined as clinical, radiologic and/or pathologic evidence of systemic disease at sites including, but not limited to the liver, lungs, peritoneum and para-aortic region. DFS and OS were determined depending on the stage (Table I). Evolution was defined as disease progression out of adjuvant therapy, chemoresistance as disease progression under or after
Table I. Patients characteristics.

A, Global patients clinicopathological characteristics

\begin{tabular}{lcc}
\hline Characteristics & $\mathrm{n}$ & $\%$ \\
\hline Gender & & \\
Male & 44 & 54 \\
Female & 38 & 46 \\
pTNM stage & & \\
I & 6 & 7.3 \\
II & 35 & 42.7 \\
III & 27 & 33 \\
IV & 14 & 17 \\
Age (years) & & \\
$<70$ & 24 & 29.3 \\
$>70$ & 58 & 70.7 \\
ASA scores & & 67.1 \\
1-2 & 55 & 32.9 \\
$3-4$ & 27 & \\
\hline
\end{tabular}

B, Patient outcome for the two analysis

\begin{tabular}{lrrrrr}
\hline & \multicolumn{2}{c}{$\begin{array}{c}\text { First } \\
\text { follow-up }\end{array}$} & & \multicolumn{2}{c}{$\begin{array}{c}\text { Second } \\
\text { follow-up }\end{array}$} \\
\cline { 2 - 3 } Patient outcome & $\mathrm{n}$ & $\%$ & & $\mathrm{n}$ & $\%$ \\
\hline Overall survival & $\mathbf{4 9}$ & $\mathbf{5 9 . 8}$ & $\mathbf{3 9}$ & $\mathbf{4 9 . 6}$ \\
Recurrence-free survival & 43 & 52.4 & 38 & 48.1 \\
Disease-specific survival & 6 & 7.3 & & 1 & 1.5 \\
Total death & $\mathbf{3 3}$ & $\mathbf{4 0 . 2}$ & $\mathbf{4 0}$ & $\mathbf{5 0 . 6}$ \\
Death due to CRC & 20 & 24.4 & & 25 & 31.6 \\
Death due to other causes & 13 & 15.8 & 15 & 19.0
\end{tabular}

${ }^{\mathrm{a}}$ September 1, 2009; ${ }^{\mathrm{b}}$ December 15, 2010.

adjuvant therapy and remission was defined when no clinical sign of disease progression was observed.

Tissue analysis. The resected specimens were subjected for classic pathologic assessment with the pTNM system (3). Histological slides were reviewed to identify normal-appearing areas and also tumor areas, excluding necrotic central tumor zone. Archived, formalin-fixed, paraffin-embedded blocks of tissues were obtained from the Pathology Department, sectioned ( $4 \mu \mathrm{m}$ in thickness) and stained with hematoxylin eosin safran (HES) for diagnosis and pTNM grading as well as for immunostaining.

Immunohistochemistry. All antibodies used were previously assessed by immunohistochemistry [for DR4 and DR5 (18); for cleaved caspase-3 (19)] or by Western blot analysis [for AIF (20); for cleaved caspase-3 (21)]. The antibodies p53 and Ki-67 are routinely used by the Pathology Department. 
Table II. Technical parameters used for immunohistochemistry experiments.

\begin{tabular}{|c|c|c|c|}
\hline Antibody name (origin) & Diluent solution & IHC dilution & Revelation system (origin) \\
\hline \multicolumn{4}{|l|}{ DR5 for manual IHC (Calbiochem, PC392) } \\
\hline $\begin{array}{l}\text { A rabbit polyclonal antibody which recognizes } \\
\text { a synthetic peptide corresponding to amino acids } \\
388-407 \text { of human DR5 precursor }\end{array}$ & PBS-BSA $3 \%$ & $1: 800$ & $\begin{array}{l}\text { Anti-rabbit HRP EnVision }{ }^{\mathrm{TM}+} \\
\text { system and DAB } \\
\text { (DakoCytomation SA) }\end{array}$ \\
\hline \multicolumn{4}{|l|}{$\begin{array}{l}\text { p53 for automated IHC (M 7001, } \\
\text { DakoCytomation) }\end{array}$} \\
\hline $\begin{array}{l}\text { Anti-p53 that matched wild-type and } \\
\text { mutant-type p53 protein }\end{array}$ & $\begin{array}{c}\text { Diluent solution } \\
\text { (Ventana Medical Systems) }\end{array}$ & $1: 50$ & $\begin{array}{l}\text { BenchMark Technology } \\
\text { (Ventana Medical Systems) }\end{array}$ \\
\hline
\end{tabular}

Details for immunohistochemistry are listed in Table II. For manual immunohistochemistry, paraffin sections were deparaffinized in toluene, alcohol and rehydrated with phosphatebuffered saline (PBS). Before staining, the sections were subjected to steam heat antigen retrieval in citrate buffer $(200 \mu \mathrm{M}$ citric acid, $9.8 \mathrm{mM}$ sodium citrate, $\mathrm{pH} \mathrm{7)}$ for $5 \mathrm{~min}$. This step was repeated four times in a microwave oven $(750 \mathrm{~W})$. After washing in PBS, the slides were incubated for 10 min with $5 \% \mathrm{H}_{2} \mathrm{O}_{2}$ in methanol to inhibit endogenous peroxidases. Non-specific sites were blocked with PBS $3 \%$ bovine serum albumin (BSA) for $30 \mathrm{~min}$. For automated immunohistochemistry, the BenchMark Technology (Ventana Medical Systems, Illkirch, France) was used. The slides were conserved with a non-aqueous mounting medium. The sections were examined with a Zeiss microscope and the images were acquired with a Zeiss camera.

To test the specificity of staining, negative control experiments were performed either by omitting primary antibody, by substituting primary antibody with a non-immune serum or by omitting both primary antibody and secondary antibody. Non-specific staining was not observed (data not shown).

TUNEL assay. The DeadEnd ${ }^{\mathrm{TM}}$ colorimetric TUNEL system (Promega, Charbonnières-les-Bains, France) was used to end-label the fragmented DNA of apoptotic cells. The reaction is based on the incorporation of biotinylated nucleotide at the 3'-OH DNA ends using the terminal deoxynucleotidyl transferase recombinant (rTdT) enzyme activity. The enzymatic reaction was made as described by the manufacturers. Finally, sections were lightly counterstained with hematoxylin.

Quantification of immunostaining. The most homogeneous stained areas of each slide were selected for quantification. Immunoreactivity was scored by cell percentages: $0,25,50$ and $75 \%$ of cells. Three independent examinations were made on each slide by two individuals.

Statistical analysis. Overall variations in staining percentages and their relationship with tumor grade were evaluated by analyses of variance using SYSTAT 12.0 (SPSS, 2007). Tukey's post-hoc test was used to assess the significance of differences and P-value $<0.05$ was considered as significant. Correlations between parameters were calculated using Spearman Rho and
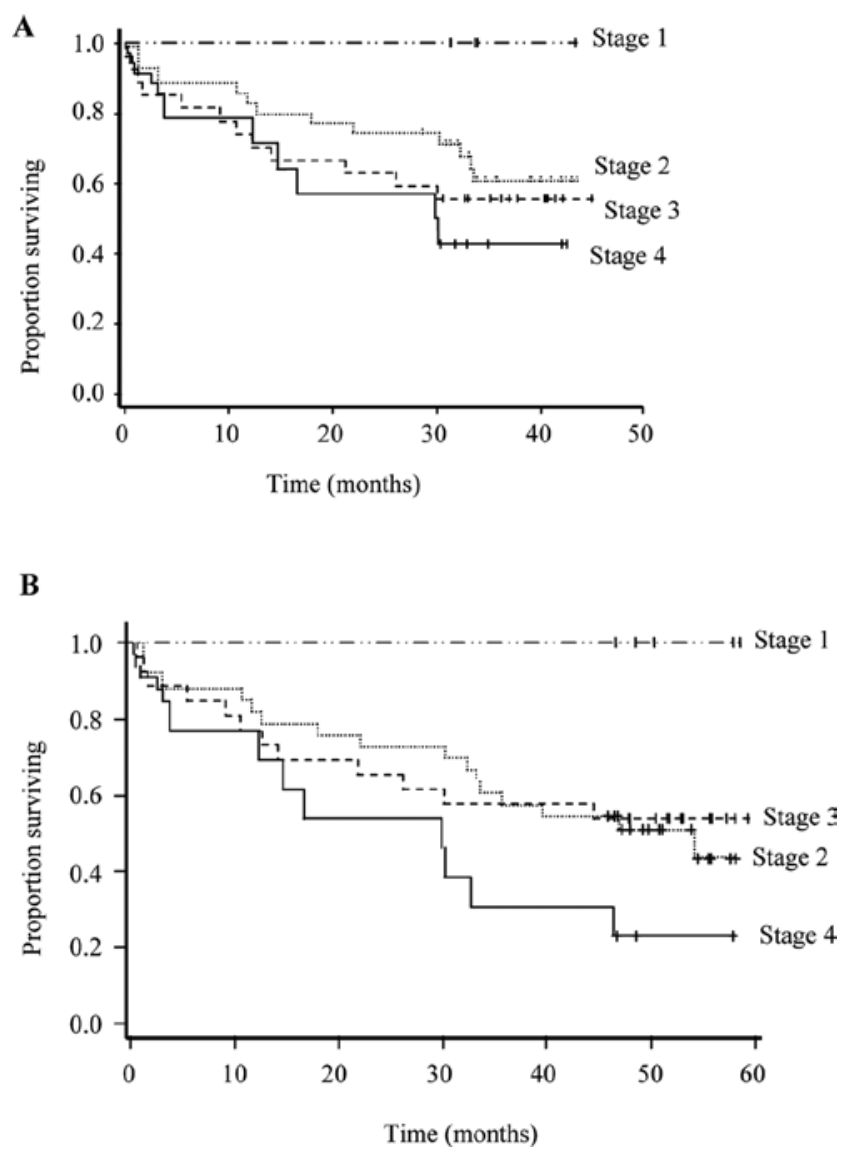

Figure 1. Global survival of CRC patients based on tumor stages. (A) Analysis made at the first follow-up. The estimated relative risk is 1.55 (RR); the standard error is 0.312 ( $\mathrm{SE}$ ), $\mathrm{P}=0.029$. (B) Analysis made at the second follow-up. The estimated relative risk is $1.55(\mathrm{RR})$; the standard error is 0.295 (SE), $\mathrm{P}=0.022$.

conducted with PAST 1.83 (22). Survival curves were made by using the free access related to Dartmouth-Hitchcock Norris Cotton Cancer Center (http://biostat.hitchcock.org/BSR/ Analytics/CompareTwoSurvivalDistributions.asp).

\section{Results}

Clinicopathological characteristics and patient outcome. The studied population was composed of 82 patients (44 men, $54 \%$ 

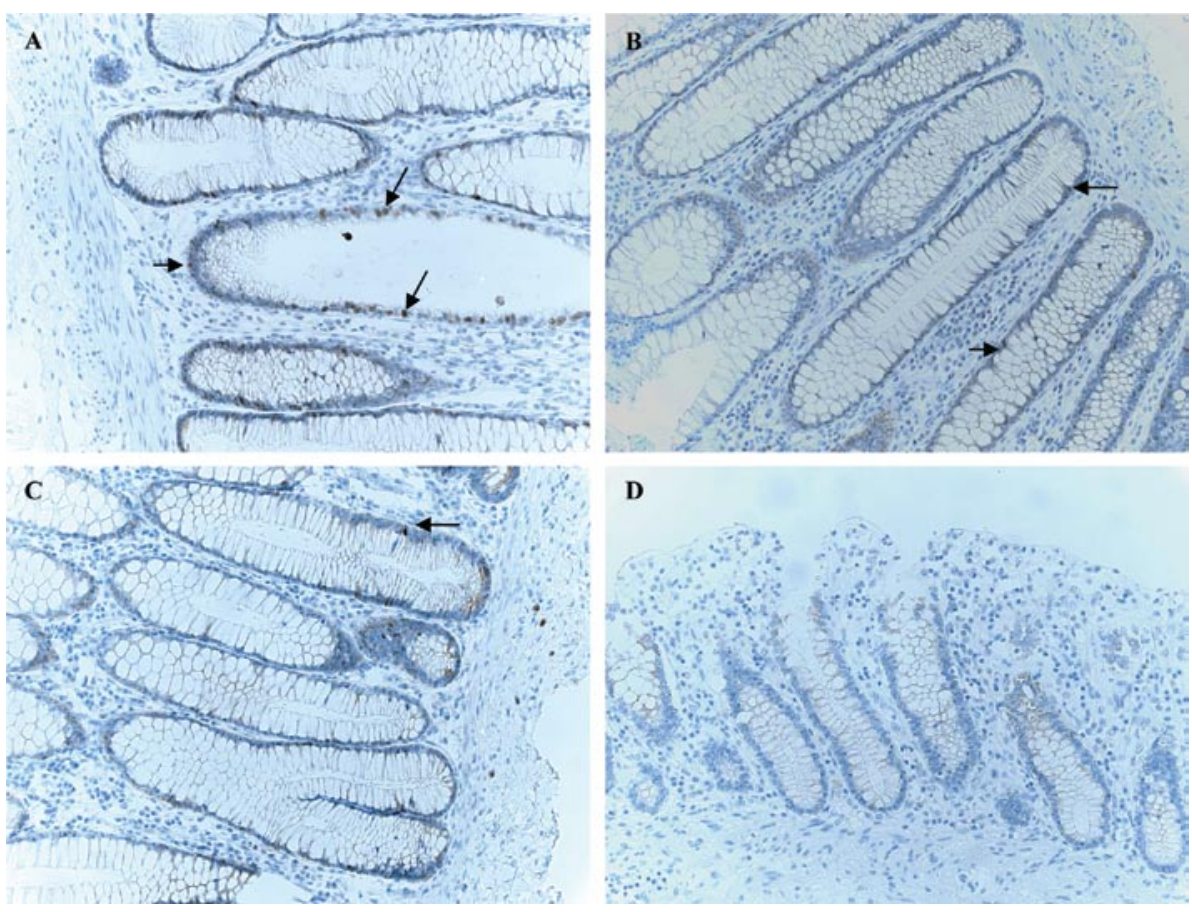

Figure 2. Immunohistochemical localization of p53 in NT areas of different CRC stages. Immunohistochemical staining on paraffin-embedded sections (4 $\mu \mathrm{m}$ ), using primary antibody against p53 (1:50; M 7001, DakoCytomation, SA) and BenchMark Technology (Ventana Medical Systems). Original magnification was x200. (A) Stage I; (B) Stage II; (C) Stage III; (D) Stage IV.

and 38 women, $46 \%$ ) who were not treated before the surgical intervention. Forty-one patients were low grade (Stages I and II) and 41 had high-grade CRC (Stages III and IV) as described in Table IA.

At the first analysis, 24 were $<70$ year-old and 58 patients $>70$ year-old (Table IA). During our study, the OS rate was $59.8 \%$ (49 patients) among which there were 43 patients $(52.4 \%)$ who had no recurrence and 6 patients $(7.3 \%)$ had recurrence of CRC. Moreover, 33 patients died (40.2\%) either because of the CRC (20 patients, $24.4 \%$ ) or due to other disease (13 patients, $15.8 \%$ ). The ASA (American Society of Anaesthesiologists) scores were determined: 55 patients were score 1-2 (6 patients had score 1: 2 Stage II and 4 Stage III; 49 had score 2: 3 Stage I, 21 Stage II, 13 Stage III and 12 Stage IV) and 27 had score 3-4 (3 Stage I, 12 Stage II, 10 Stage III and 2 Stage IV) (Table IB).

Fifteen months later, at the second evaluation, 79 patients were evaluated (three were lost to follow-up). The OS rate was 49\%: patient survival was $100 \%$ for Stage I, $48 \%$ for Stage II, $54 \%$ for Stage III and $23 \%$ for Stage IV. Except for five patients of Stage II whose deaths were not related to cancer, 5 patients died (2 of Stage II, 1 of Stage III and 2 of Stage IV) because of their CRC between the first and the second time of analysis (Table IB). The global survival of patients based on CRC stages for the two analyses is presented in Fig. 1.

Immunohistochemical and statistical analysis. Because proliferation, alteration and/or suppression of apoptosis have an important impact on CRC initiation and development (4), we studied proteins involved in these processes. An immunohistochemical study was carried out using antibodies which recognize extrinsic as well as intrinsic proteins. We chose to use the detection of cleaved caspase- 3 and the DNA fragmentation by the TUNEL analysis, useful and complementary methods permitting to establish if a cell has undergone apoptosis. The 'Control group', was first evaluated for the constitutional expression of proteins and was then studied in the NT tissue of each patient, which served as an internal control, before being studied in $\mathrm{T}$ areas. In fact, each patient was its own control.

Significant data were only obtained for the expression of p53 and DR5, as discussed below. Surprisingly, no correlation was found between apoptotic protein expression and response to treatment of patients $(\mathrm{P}>0.05)$.

The p53 expression in non-tumor areas is linked to advanced stages of $C R C$. The p53 protein is a DNA binding cell cycleregulating transcription factor that participates in the balance between cell survival and death, which is the main intrinsic factor inducing apoptosis by recognizing the external stimuli and driving an irreversible series of events, including structural and morphological changes. Although the mutated protein is the more easily detected form by immunohistochemistry (23), the expression of p53 observed in the NT areas is certainly in part due to the damage caused by ischemia during the time of surgical intervention. The p53 expression is observed in the nucleus as well as in the cytoplasm of cells (Fig. 2). It is present from $50 \%$ (24) to $75 \%$ of CRC patients cells $(12,25)$, as we also found for the $\mathrm{T}$ areas in our study $(52 \% ; \pm 24.8 \%)$. Moreover, a significant decrease in expression of this protein was found in NT tissues in function of CRC stages (Fig. 3, $\mathrm{P}=0.0035$ for the first follow-up and $\mathrm{P}=0.019$ for the second follow-up), reinforcing the fact that the p53 expression could be used as a prognostic marker and also as a CRC advanced stage indicator. 


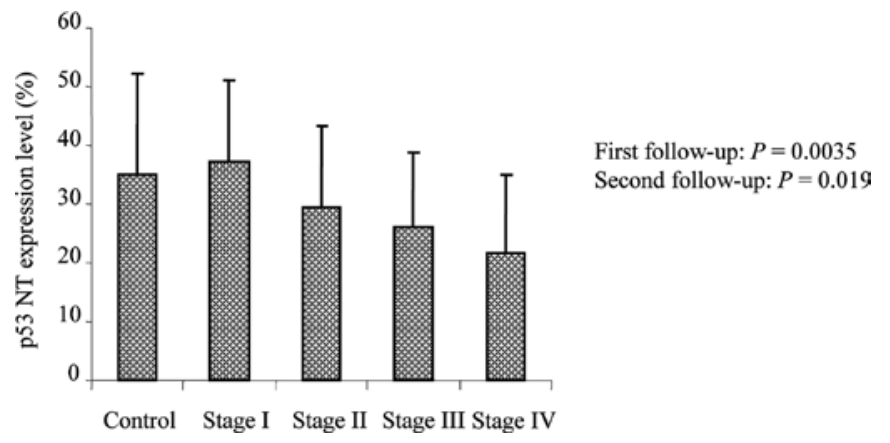

Figure 3. Analysis of p53 expression in NT areas of patients with different CRC stages in comparison with its expression in the 'Control group'. Each value corresponds to the medium obtained by quantification of the immunostaining for NT tissue of all patients, as described in Materials and methods Control mean 35 \pm 17.5 ; Stage I mean 37.5 \pm 13.7 ; Stage II mean 29.3 \pm 14.2 ;

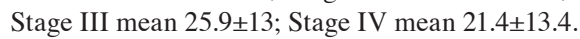

The DR5 expression in tumor areas is associated with the advanced stages of CRC. TRAIL (tumor necrosis factor related apoptosis inducing ligand) activates apoptosis through the death receptors DR4 (TRAIL-R1) or DR5 (TRAIL-R2) which carry cytoplasmic death domains (26). The expression of DR4 and DR5 by immunohistochemical analysis are cytoplasmic (18), as in our work (Fig. 4). More particularly for DR5, when each stage is examined independently and compared with the others, our results showed that the expression decreased with tumor stages (Fig. 5; $\mathrm{P}=0.027$ for the first follow-up and $\mathrm{P}=0.032$ for the second follow-up), suggesting that DR5 would be a marker for tumor progress of CRC. No correlation between the survival rate based on the patient response to treatment and DR5 expression was found.

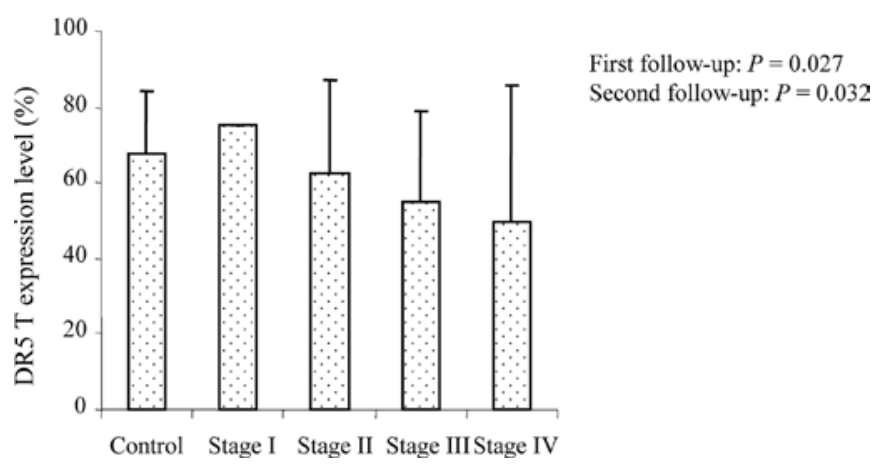

Figure 5. Analysis of DR5 expression in T areas of patients with different CRC stages. Each value corresponds to the medium obtained by quantification of the immunostaining for $\mathrm{T}$ tissue of all patients, as described in Materials and methods. Control mean 67.5 \pm 16.9 ; Stage I mean $75 \pm 0$; Stage II mean

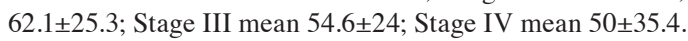

\section{Discussion}

The colon is part of the organs that have an important rate of renewal. The number of epithelial cells has to be kept constant to maintain the intestinal homeostasis in all situations. Therefore, an important balance between proliferation and apoptosis is present, probably influenced by individual variability.

Because it is well known that apoptosis reflects both proliferative activity and cell death $(27,28)$, we chose to explore cell proliferation by the expression of Ki-67 and the cell death with proteins implicated in apoptosis (p53, AIF, DR4, DR5 and cleaved caspase-3) in association with the TUNEL analysis. After being validated on the 'Control group'
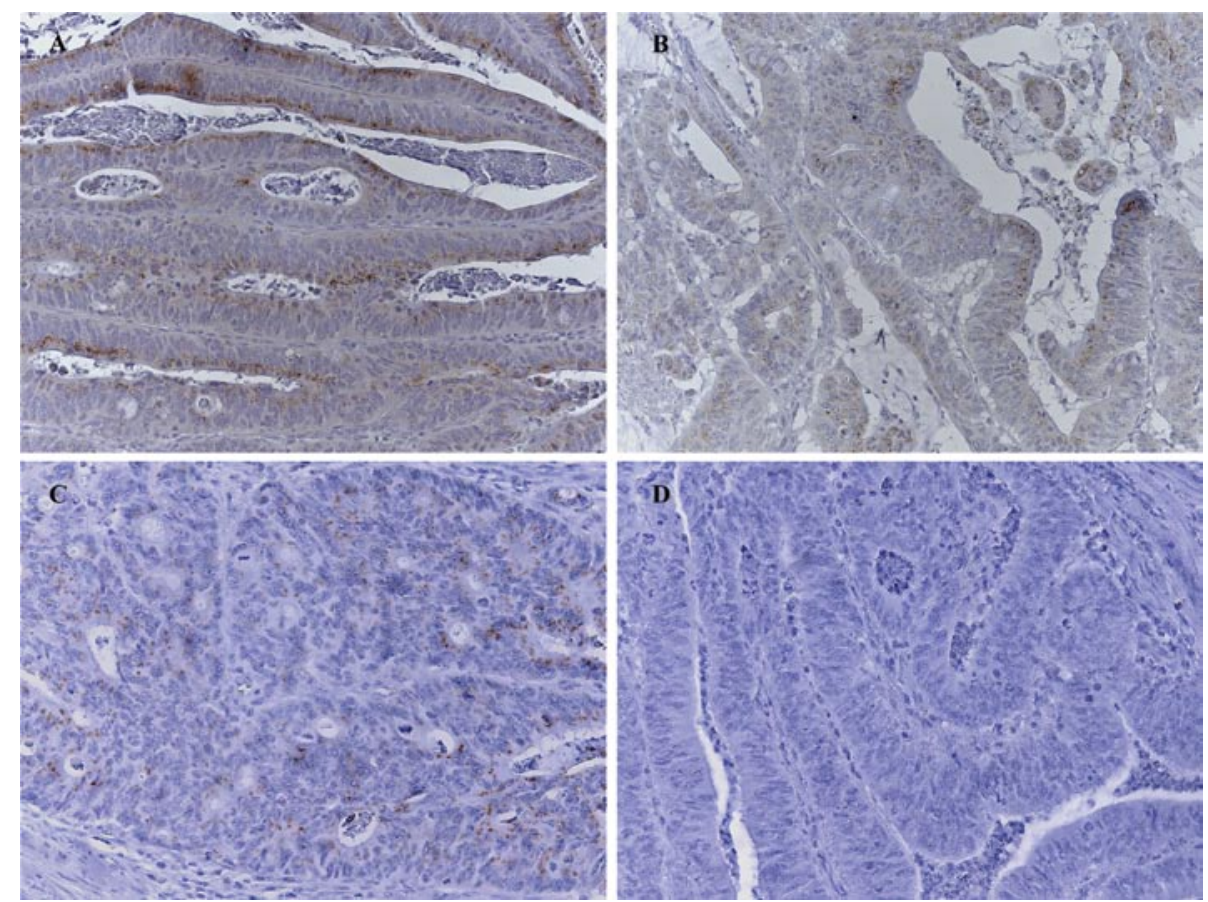

Figure 4. Immunohistochemical localization of DR5 in T areas of different CRC stages. Immunohistochemical staining was made on paraffin-embedded sections (4 $\mu \mathrm{m})$, using primary antibody against DR5 (1:800; Calbiochem, PC392) and anti-rabbit HRP EnVision ${ }^{\mathrm{TM}+}$ system and DAB (DakoCytomation). Original magnification was x200. (A) Stage I; (B) Stage II; (C) Stage III; (D) Stage IV. 
to obtain constitutional expression, the rate of these proteins was studied in the NT tissue [or 'normal' mucosa located near the tumor which could be interpreted as the earliest stages of cancer formation (2)] and also in the $\mathrm{T}$ tissue of each patient. Finally, these expressions were correlated with personal parameters.

Our results show a clear decrease in the p53 expression in NT tissues with the progress of CRC stage by stage (Figs. 2 and $3 ; \mathrm{P}=0.0035$ for the first follow-up and $\mathrm{P}=0.019$ for the second follow-up). Given that a comparative result has been found by Gurzu and co-workers in $\mathrm{T}$ tissues, these data suggest that a weak expression of p53 is correlated with advanced stages (29). Obtained in the NT tissue, our original finding could be explained by a diminution of the apoptotic process usually found in the first steps of carcinogenesis, driving to an accumulation of damaged cells, linked to the cell death resistance, and finally to the development of carcinoma $(2,30)$. Moreover, the future detection of p53 in non-cancerous tissues (as polyps for example) could help identifying people with a major risk for developing cancer because the lower the p53 expression, the higher the risk is.

Without making a distinction between CRC stages, DR4 and DR5 are increasingly expressed by tumor cells (18,31-33). However, contrary to a recent study (32), a clear correlation between DR5 expression and the different CRC stages (taken one by one) was found in our work (Fig. 5; $\mathrm{P}=0.027$ for the first follow-up and $\mathrm{P}=0.032$ for the second follow-up), reinforcing the idea that inhibition of the apoptosis process comes with CRC progression. This different result was probably obtained because of the higher number of patients included in our study (82 vs. 51) in addition to a 'Control group', and also to the immunohistochemical method employed reflecting more the in vivo disease than molecular biology. Because TRAIL has a better affinity to fix DR5 in physiologic conditions (13), it certainly contributes more than DR4 to induction of apoptosis. Our data suggest a decrease in the initiation of apoptosis by the extrinsic pathway due to the decreased expression of DR5 during the CRC development stage by stage. This phenomenon comes certainly in addition to the existence of Decoy TRAIL receptors (13) to explain the resistance to apoptosis.

Finally, in accordance with Bedi and co-workers, our results suggest a reduction of apoptosis in advanced stages of CRCs in NT and T tissues that may contribute to tumor growth, clonal evolution and inherent resistance to chemotherapeutic agents (34). Taken together, these data support the finding that when apoptosis is weak, a rapid progression of the disease may be observed (30). Like other published works (30,35-37), no correlation between the status of studied proteins and response to treatment of patients was found in our study.

Even if apoptosis, is the mechanism targeted by chemotherapeutic treatment, our work reinforces the fact that proteins implicated in proliferation and apoptosis are independent prognostic factors in the case of CRC, except for p53 and DR5 which could be used as indicators of stage progress.

\section{Acknowledgements}

Authors gratefully acknowledge the University of Limoges, La Ligue contre le Cancer and the Région Limousin for financial support given by the CORC (Comité Orientation Recherche Cancer). H.A. profits from a pre-doctoral fellowship from the Région Limousin. We express our gratitude to the surgical teams (Professor A. Gainant and Professor D. Valleix), and in particular to the technical experts of the Pathology Department of the Limoges University Hospital for their helpful advice on immunohistochemistry. We thank 'La tumorothèque du Limousin' for providing samples.

\section{References}

1. Parkin DM, Bray F, Ferlay J and Pisani P: Global cancer statistics, 2002. CA Cancer J Clin 55: 74-108, 2005.

2. West NJ, Courtney ED, Poullis AP and Leicester RJ: Apoptosis in the colonic crypt, colorectal adenomata, and manipulation by chemoprevention. Cancer Epidemiol Biomarkers Prev 18: 1680-1687, 2009.

3. Greene FL, Page DL, Fleming ID, Fritz A, Balch CM, Haller DG and Morrow M (eds): AJCC (American Joint Committee on Cancer) Cancer Staging Manual. 6th edition. Springer-Verlag, New York, pp113, 2002.

4. Hector S and Prehn JH: Apoptosis signaling proteins as prognostic biomarkers in colorectal cancer: a review. Biochim Biophys Acta 1795: 117-129, 2009.

5. Reed JC: Drug insight: cancer therapy strategies based on restoration of endogenous cell death mechanisms. Nat Clin Pract Oncol 3: 388-398, 2006.

6. Kerr JF, Wyllie AH and Currie AR: Apoptosis: a basic biological phenomenon with wide-ranging implications in tissue kinetics. Br J Cancer 26: 239-257, 1972.

7. Hengartner MO: The biochemistry of apoptosis. Nature Lett 407: 770-776, 2000.

8. Luo X, Budihardjo I, Zou H, Slaughter C and Wang X: Bid, a $\mathrm{Bcl} 2$ interacting protein, mediates cytochrome c release from mitochondria in response to activation of cell surface death receptors. Cell Death Differ 94: 481-490, 1998.

9. Candé C, Cohen I, Daugas E, et al: Apoptosis-inducing factor (AIF): a novel caspase-independent death effector released from mitochondria. Biochimie 84: 215-222, 2002.

10. Jeong EG, Lee JW, Soung YH, et al: Immunohistochemical and mutational analysis of apoptosis-inducing factor (AIF) in colorectal carcinomas. APMIS 114: 867-873, 2006.

11. Hickman JA: Different cell thresholds for commitment to death: a link between carcinogenesis and drug resistance. Drug Resist Updat 1: 84-85, 1998.

12. Prabhudesai SG, Rekhraj S, Roberts G, Darzi AW and Ziprin P: Apoptosis and chemo-resistance in colorectal cancer. J Surg Oncol 96: 77-88, 2007.

13. Van Geelen CM, De Vries EG and De Jong S: Lessons from TRAIL-resistance mechanisms in colorectal cancer cells: paving the road to patient-tailored therapy. Drug Resist Updat 7: 345-358, 2004.

14. Nachmias B, Ashhab Y and Ben-Yehuda D: The inhibitor of apoptosis protein family (IAPs): an emerging therapeutic target in cancer. Semin Cancer Biol 14: 231-243, 2004.

15. Koornstra JJ, De Jong S, Hollema H, De Vries EG and Kleibeuker JH: Changes in apoptosis during the development of colorectal cancer: a systematic review of the literature. Crit Rev Oncol Hematol 45: 37-53, 2003.

16. Gavrieli Y, Sherman Y and Ben-Sasson SA: Identification of programmed cell death in situ via specific labeling of nuclear DNA fragmentation. J Cell Biol 119: 493-501, 1992.

17. Desch CE, Somerfield MR, Krause C, et al: Colorectal cancer surveillance: 2005 update of an American Society of Clinical Oncology practice guideline. J Clin Oncol 23: 8512-8519, 2005.

18. Koornstra JJ, Kleibeuker JH, van Geelen CM, et al: Expression of TRAIL (TNF-related apoptosis-inducing ligand) and its receptors in normal colonic mucosa, adenomas, and carcinomas. J Pathol 200: 327-335, 2003.

19. Gown AM and Willingham MC: Improved detection of apoptotic cells in archival paraffin sections: immunohistochemistry using antibodies to cleaved caspase 3. J Histochem Cytochem 50: 449-454, 2002.

20. Wu CH, Rastegar M, Gordon J and Safa AR: beta(2)-microglobulin induces apoptosis in HL-60 human leukemia cell line and its multidrug resistant variants overexpressing MRP1 but lacking Bax or overexpressing P-glycoprotein. Oncogene 20: 7006-7020, 2001. 
21. Martin L, Magnaudeix A, Esclaire F, Yardin C and Terro F Inhibition of glycogen synthase kinase-3beta down-regulates total tau proteins in cultured neurons and its reversal by the blockade of protein phosphatase-2A. Brain Res Dev Brain Res 3: 66-75, 2009.

22. Hammer $\varnothing$, Harper DAT and Ryan PD: PAST: Paleontological Statistics Software Package for Education and Data Analysis. Palaeontologia Electronica 4: p9, 2001

23. Fu CG, Tominaga O, Nagawa $\mathrm{H}$, et al: Role of $\mathrm{p} 53$ and $\mathrm{p} 21 /$ WAF1 detection in patient selection for preoperative radiotherapy in rectal cancer patients. Dis Colon Rectum 41: 68-74, 1998.

24. Iacopetta B: TP53 mutation in colorectal cancer. Hum Mutat 21 271-276, 2003.

25. Yang SY, Sales KM, Fuller B, Seifalian AM and Winslet MC: Apoptosis and colorectal cancer: implications for therapy. Trends Mol Med 15: 225-233, 2009.

26. Griffith TS and Lyncht DH: TRAIL: a molecule with multiple receptors and control mechanisms. Curr Opin Immunol 10: 559-563, 1998

27. Tsamandas AC, Kardamakis D, Tsiamalos P, et al: The potential role of Bcl-2 expression, apoptosis and cell proliferation (Ki-67 expression) in cases of gastric carcinoma and correlation with classic prognostic factors and patient outcome. Anticancer Res 29: 703-709, 2009.

28. Scopa CD, Tsamandas AC, Zolota V, Kalofonos HP, Batistatou A and Vagianos C: Potential role of bcl-2 and ki-67 expression and apoptosis in colorectal carcinoma: a clinicopathologic study. Dig Dis Sci 48: 1990-1997, 2003.

29. Gurzu S, Jung J, Mezei T and Pávai Z: The correlation between the immunostains for p53 and Ki67 with bcl-2 expression and classical prognostic factors in colorectal carcinomas. Rom J Morphol Embryol 48: 95-99, 2007.
30. Ivanov K, Kolev N, Tonev A, et al: Comparative analysis of prognostic significance of molecular markers of apoptosis with clinical stage and tumor differentiation in patients with colorectal cancer: a single institute experience. Hepatogastroenterology 56: 94-98, 2009.

31. Daniels RA, Turley H, Kimberley FC, et al: Expression of TRAIL and TRAIL receptors in normal and malignant tissues. Cell Res 15: 430-438, 2005 .

32. Oikonomou E, Kosmidou V, Katseli A, et al: TRAIL receptor up-regulation and the implication of KRAS/BRAF mutations in human colon cancer tumors. Int J Cancer 125: 2127-2135, 2009.

33. Van Geelen CM, Westra JL, De Vries EG, et al: Prognostic significance of tumor necrosis factor-related apoptosis-inducing ligand and its receptors in adjuvantly treated stage III colon cancer patients. J Clin Oncol 24: 4998-5004, 2006.

34. Bedi A, Pasricha PJ, Akhtar AJ, et al: Inhibition of apoptosis during development of colorectal cancer. Cancer Res 55: 1811-1816, 1995.

35. Kim NK, Park JK, Lee KY, et al: p53, BCL-2, and Ki-67 expression according to tumor response after concurrent chemoradiotherapy for advanced rectal cancer. Ann Surg Oncol 8: 418-424, 2001.

36. El-Awady S, Morshed M, El-Shobaky M, Abo-Hashem M and Ghazy H: Potential role of bcl-2 expression and apoptotic body index in colorectal cancer. Hepatogastroenterology 55: 76-81, 2008.

37. Menezes HL, Jucá MJ, Gomes EG, Nunes BL, Costa HO and Matos D: Analysis of the immunohistochemical expressions of p53, bcl-2 and Ki-67 in colorectal adenocarcinoma and their correlations with the prognostic factors. Arq Gastroenterol 47: 141-147, 2010. 